\title{
A Neurose da Sociedade e a Motivação de uma Sentença Criminal Condenatória
}

\author{
The Neurosis of Society and the Motivation of a Condenatory \\ Criminal Sentence
}

\author{
Daniel Soares de Jesus Pinheiro ${ }^{1}$ \\ Renata Almeida da Costa ${ }^{2}$
}

\begin{abstract}
Resumo: Este trabalho aborda o tema do encarceramento. Tratar sobre esse tema é tratar sobre um assunto delicado e importante. Bastante delicado, mas não tão importante, para quem deveria dar (mas não dá) uma solução adequada ao problema. E muito importante, mas não tão delicado, para quem vivência o encarceramento na própria pele, afinal, delicadeza não encontraria muito espaço em prisões lotadas. Entendendo ser necessário tratar sobre esse tema, buscou-se resposta ao problema: o que motiva uma sentença criminal condenatória? Dessa forma, o trabalho foi desenvolvido com o objetivo geral de compreender a motivação do magistrado para proferir uma sentença criminal condenatória. Para tanto, foram estabelecidos os objetivos específicos a) apresentar como o cenário jurídico mais recente do Brasil é apresentado à sociedade; e b) analisar a relação magistrado/sociedade a partir da teoria sociológica de Pierre Bourdieu. O presente trabalho foi realizado com apoio da Coordenação de Aperfeiçoamento de Pessoal de Nível Superior - Brasil (CAPES) - Código de Financiamento 001.
\end{abstract}

Palavras-chave: Campo jurídico. Encarceramento. Habitus. Magistratura.

\begin{abstract}
This paper addresses the theme of incarceration. To deal with this topic is to address a sensitive and important subject. Quite delicate, but not so important, for those who should give (but don't give) a proper solution to the problem. It is very important, but not so delicate, for those who experience incarceration in their own skin, after all, delicacy would not find much space in crowded prisons. Understanding that it is necessary to address this issue, we sought to answer the problem: what motivates a convicting criminal sentence? Thus, the work was developed with the general objective of understanding the magistrate's motivation to make a condemnatory criminal sentence. To this end, the specific objectives were established: a) to present how the most recent legal scenario in Brazil is presented to society; and b) analyze the relation magistrate/society from the sociological theory of Pierre Bourdieu. This study was financed in part by the Brazilian Coordination for the
\end{abstract}

\footnotetext{
${ }^{1}$ Mestre em Direito pela Universidade La Salle - Canoas/RS. Especialista em Direito Civil e Processual Civil pelo Centro Universitário Ritter dos Reis.

2 Pós-Doutora pelo Instituto Internacional de Sociologia Jurídica de Oñati, IISJ, Espanha. Doutora em Direito pela UNISINOS. Mestre em Ciências Criminais pela Pontifícia Universidade Católica do Rio Grande do Sul. Professora e coordenadora do Programa de Pós-Graduação em Direito (Mestrado e Doutorado) da Universidade La Salle - Canoas/RS e professora do curso de Graduação em Direito.
} 
Improvement of Higher Education Personnel (CAPES, in the portuguese acronym) - Finance Code 001.

Keywords: Legal field. Incarceration. Habitus. Magistrature.

\section{Introdução}

"Agora, eu percebia que as leis e as estruturas teoricamente destinadas a proteger o cidadão podem, em determinadas circunstâncias, se voltar contra ele" (HULSMAN, 1997, p. 23). Hulsman percebeu isso da pior forma possível, na própria pele, quando a polícia de seu país, a Holanda, o prendeu e enviou para um campo de concentração na Alemanha no período da guerra. Através dessa experiência "[...] descobri a falsidade do discurso oficial que, de um lado, pretende ser o Estado necessário à sobrevivência das pessoas e, de outro lado, o legitima, revestindo-o da representatividade popular" (HULSMAN, 1997, p. 23). Mais do que isso, Hulsman descobriu que sua educação e o discurso político o haviam enganado.

Mas hoje a sociedade e os Estados são muito diferentes daqueles da primeira metade do século passado, ou não? Até que ponto a sociedade evoluiu? Até que ponto as experiências com os erros históricos ajudam a conscientizar a sociedade e o Estado? Os presídios talvez estejam entre as maiores evidências de que a sociedade não se transformou tanto assim. Tanto a prisão de Hulsman em um campo de concentração, quanto as prisões de milhares de pessoas em presídios brasileiros são escolhas do Estado, e são manifestações violentas das leis e das estruturas teoricamente destinadas a proteger o cidadão, as quais se exercem sobre o próprio corpo do cidadão aprisionado.

Tratar sobre o tema "encarceramento" sempre será tratar sobre um assunto delicado e importante. Bastante delicado, mas não tão importante, para quem deveria dar (mas não dá) uma solução adequada ao problema. E muito importante, mas não tão delicado, para quem vivência o encarceramento na própria pele, afinal, delicadeza não encontraria muito espaço em celas lotadas. 
O encarceramento é um tema que requisita atenção do pesquisador crítico. Não se está tratando apenas de um assunto importante para quem está preso, está-se tratando de um assunto que atinge a todos como sociedade, de modo que "[...] proteger o um é proteger o todo, não há todo sem o um. Ao proteger os direitos do um - seja quem for, seja qual o delito cometido - se está protegendo a própria sociedade da qual o um é parte indissociável” (CARVALHO, 2017, p. 11). Portanto, entende-se ser necessário tratar sobre o tema. Neste trabalho se buscou, então, resposta ao problema: o que motiva uma sentença criminal condenatória?

Cabe ressaltar que o que é apresentado neste trabalho é a primeira parte do resultado de uma pesquisa desenvolvida junto à magistratura criminal gaúcha entre os anos de 2018 e 2019. Além do estudo trazido aqui, a referida pesquisa tratou sobre a institucionalização da justiça restaurativa pelo Poder Judiciário e sobre o olhar da magistratura criminal gaúcha sobre a justiça restaurativa.

Esta parte da pesquisa está centrada no magistrado e na sociedade. Estabeleceu-se, então, o objetivo geral, qual seja: compreender a motivação do magistrado para proferir uma sentença criminal condenatória. Para tanto, estabeleceu-se os seguintes objetivos específicos: (a) apresentar como o cenário jurídico mais recente do Brasil é apresentado à sociedade; e (b) analisar a relação magistrado/sociedade a partir da teoria sociológica de Pierre Bourdieu. Compreende-se ser adequada a adoção da teoria de Pierre Bourdieu por conter conceitos úteis para explicação sobre a motivação de uma sentença criminal condenatória. Então, quando se explora os conceitos de habitus, campos e capital, consegue-se chegar a uma resposta adequada.

\section{A neurose da sociedade}

Cotidianamente o magistrado criminal se depara com diversos conflitos sociais, sobre eles ele tem a incumbência tomar uma decisão: 


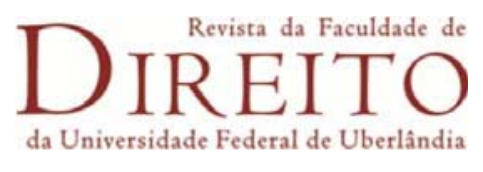

absolver ou condenar o réu. Segundo Carvalho (2017, p. 9-10) no dia em que determinar a prisão de um ser humano for apenas um ato burocrático, banal ou prazeroso, não lhe faria mais sentido ser magistrado. Ele é possuidor de um notório senso crítico sobre a naturalização do sistema de justiça criminal, e com isso vem a sua preocupação com a pessoa que está sendo julgada. Quanto ao restante da magistratura não seria possível afirmar que demonstra possuir tamanha preocupação, pelo contrário, algumas decisões judiciais podem passar a impressão de uma certa indiferença por parte desses funcionários públicos.

Ao ler a sentença do Processo $\mathrm{n}^{\circ}$ 001/2.17.0102577-7, do dia 06/07/2018, é possível constatar se tratar de mais um processo criminal comum, não havia nada de especial nele, a não ser a condenação que, como menciona Carvalho (2017, p. 9-10), não deveria ser vista como algo meramente burocrático. Para o réu, cujo nome se suprime para lhe tratar apenas por Dimas $^{3}$, aquele dia 6 marcaria uma data angustiante: o reconhecimento de uma dívida que ele teria de pagar à sociedade, mas que seria cobrada pelo Estado, o pagamento dessa dívida não poderia ocorrer com valores monetários, mas com meses, dias, horas e minutos de sua vida.

No caso em análise o roubo de um celular e $\mathrm{R} \$ 40,00$ de uma senhora que aguardava ônibus em um ponto da cidade de Porto Alegre foi o motivo para o Estado transformar Dimas em réu. Os bens dela foram recuperados logo em seguida, o réu, que não utilizava arma de fogo, por conta de seus atos, ou melhor, por conta de uma sentença judicial, foi condenado a quatro anos e três meses de reclusão.

Semelhantemente a Dimas, $27,58 \%$ das pessoas privadas de liberdade no Brasil respondem pelo crime de roubo, e esse índice sobe para $52,32 \%$ quando também se considera o crime de tráfico de drogas (BANCO NACIONAL DE MONITORAMENTO DE PRISÕES, 2018, p. 47). Além

\footnotetext{
${ }^{3}$ Deu-se este nome (Dimas) a ele pela semelhança que a sua história tem com a história do personagem bíblico também chamado de Dimas.
} 
disso, em julho de 2016 existiam no Brasil 726,7 mil pessoas presas (SANTOS, 2017. p. 43). Apesar de possuir números expressivos, o encarceramento, na prática, tem como responsável apenas uma categoria de funcionários públicos: a magistratura.

Diante desse cenário, indagou-se: o que estaria motivando a magistratura? A resposta poderia parecer lógica: a Lei. A Lei estaria motivando a magistratura em suas sentenças condenatórias no âmbito da justiça criminal. No entanto, acredita-se que a resposta não seria tão simples assim.Para se compreender a motivação da magistratura entendeuse necessário observar como o cenário jurídico mais recente do Brasil é apresentado à sociedade. Buscou-se, então, indícios na mídia impressa, não especializada na área do direito e que tivesse circulação nacional.

Um magistrado retratado pela mídia em geral foi Joaquim Barbosa. Ele foi considerado pela revista Veja o magistrado que mudou o Brasil, sua fama poderia ser comparada a de um artista famoso e seu rosto estava estampado em reportagens por todo o país. A menção que geralmente era feita desse magistrado tinha relação com a forma que ele enfrentava processos envolvendo políticos corruptos (ver Figura 1).

Figura 1

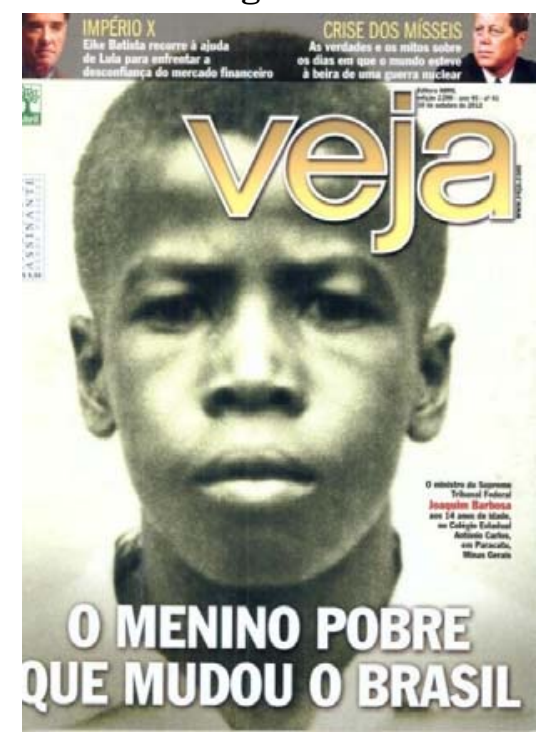

Fonte: Revista Veja, a. 45, n. 41. 
“A construção da capa auxilia no processo de construção de determinada imagem do principal 'referente' da matéria, Joaquim Barbosa" (MIQUELETTI, 2013. p. 216). De tal forma que a junção da imagem de Joaquim Barbosa com 14 anos de idade com o título da edição "O menino que mudou o Brasil” sugere “[...] a simplicidade, o que torna o público-alvo mais familiarizado com o conteúdo" (MIQUELETTI, 2013, p. 215). Ou seja, a capa passa a informação de que alguém comum, igual ao leitor, estaria realizando aquilo que o leitor não teve, até o momento, capacidade de realizar: combater políticos corruptos, daí viria a fama de Joaquim Barbosa.

Outro magistrado que ganhou publicidade foi o ex-juiz federal Sérgio F. Moro, conhecido por sua atuação como juiz responsável pelos processos da operação Lava Jato ${ }^{4}$. Sérgio Moro também ganhou destaque na capa da revista Veja. Ele foi retratado na capa da importante edição que fazia uma retrospectiva do ano de 2015. Além do rosto sério do ex-juiz, a capa traz o título "ele salvou o ano!", e abaixo considera que ele foi "a primeira esperança real de vencer a corrupção", menção bastante semelhante a que foi realizada ao ex-ministro Joaquim Barbosa (ver Figura 2).

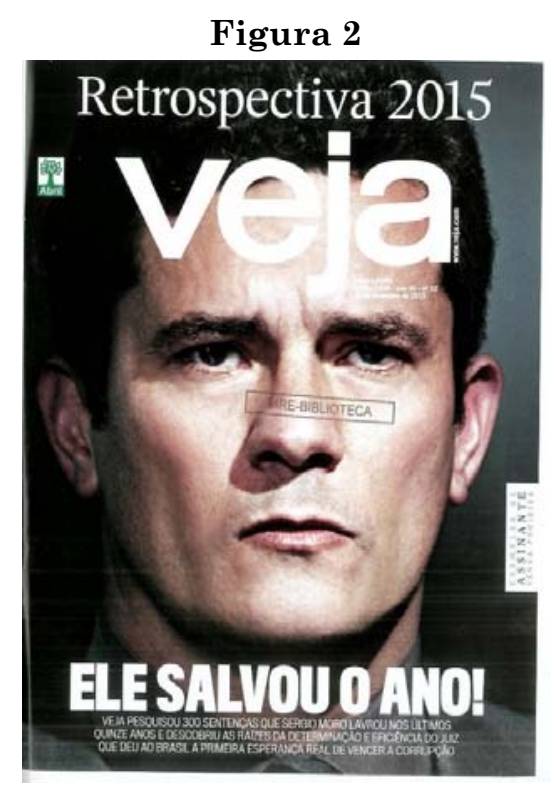

Fonte: Revista Veja, a. 48, n. 52.

\footnotetext{
${ }^{4}$ A operação Lava Jato tem sido responsável pela investigação de um esquema de corrupção envolvendo principalmente políticos e grandes empresas.
} 
Dentre os diversos políticos condenados em primeira instância pelo ex-juiz Sérgio Moro, nenhum recebeu maior destaque do que o ex-presidente do Brasil Luiz Inácio Lula da Silva, a publicidade dada ao julgamento do expresidente chamou atenção. O primeiro encontro entre o ex-juiz Sérgio Moro e o ex-presidente Lula foi retratado pela revista Veja como uma verdadeira disputa entre os dois, como se os dois fossem partes opostas no processo, como se os interesses do ex-presidente fossem opostos aos interesses do exjuiz (ver Figura 3).

Figura 3

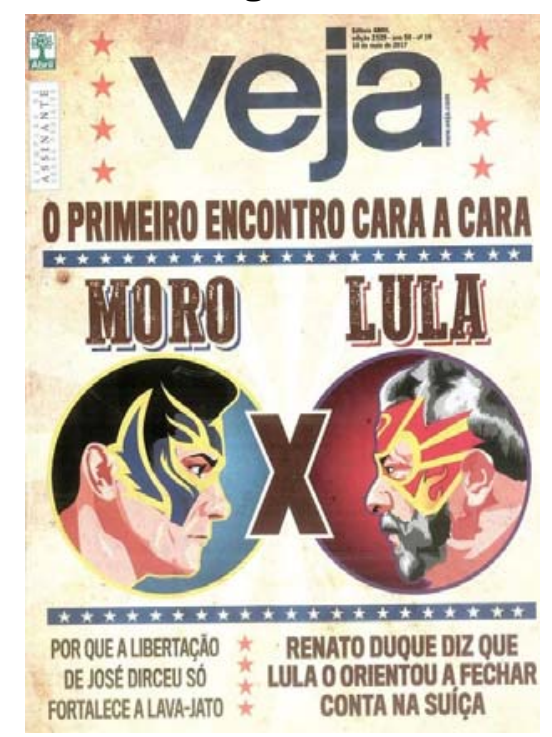

Fonte: Revista Veja, a. 50, n. 19.

Se o ex-juiz Sérgio Moro primeiramente ganhou destaque por ser considerado a esperança de vencer a corrupção, cogitar que o encontro entre ele e o ex-presidente Lula seria um confronto entre lados opostos, seria o mesmo que cogitar que a disputa a ser travada teria como representação do bem a luta de Moro contra a corrupção, e como representação do mal a tentativa de Lula de se defender das acusações contra ele levantadas. A possibilidade de ter o magistrado entrado no processo não apenas como juiz da causa, mas como parte, no sentido de tomar partido antecipadamente, desequilibra a balança da justiça. Então a acusação, representada pelo Ministério Público, que já possuía vantagem em relação ao réu, em 
decorrência de todo aparato estatal que tem a sua disposição, teria como aliado alguém mais poderoso que ambas as partes.

É importante destacar que a Veja é a revista de maior circulação nacional, e tem uma "[...] média de circulação superior a 1 milhão de exemplares por semana" (SOBREIRO, 2017). As matérias por ela publicadas, que enaltecem os ex-magistrados Joaquim Barbosa e Sérgio Moro, estão enaltecendo, na verdade, a imagem que foi construída deles como opositores da corrupção e da criminalidade.

Nesse instante se pôde perceber que a maioria dos magistrados incorpora a neurose presente na sociedade, uma "[...] fúria persecutória espetacular - outra vez, o senso comum invadindo o espaço do jurista -, transformando-o em agente da irracionalidade que percebe o fenômeno violência como espetáculo midiático" (CARVALHO, 2017, p. 10). Por outro lado, quando um magistrado decidia favoravelmente aos réus, indiferentemente de estar de acordo com a legislação vigente e de observar garantias e direitos, o magistrado provavelmente teria um tratamento diferenciado. Os holofotes postos sobre ele já não seriam para aclamar uma possível decisão revestida de legalidade, mas para colocar sob sua responsabilidade a reprodução da corrupção e da criminalidade na sociedade, como a publicidade dada ao ministro do STF Gilmar Ferreira Mendes na capa da revista Veja.

A revista Veja apresentou na capa o rosto do ministro Gilmar Mendes com o título "o juiz que discorda do Brasil”, abaixo atribuiu a ele a frustração de um país "[...] que quer acabar com a tradição de corrupção e impunidade" (ver Figura 4). Não se teve a intenção de defender ou rechaçar esse ou aquele magistrado, pretendeu-se apenas demonstrar que atualmente a sociedade se identifica com os magistrados que supostamente nela se espelham, independentemente de suas decisões estarem revestidas de legalidade ou não. Vale mais para a sociedade, ou pelo menos para a parcela considerável dela, uma decisão que atenda os seus desejos de punição, do 
que uma decisão que respeite garantias e direitos dos réus e desperte nela a sensação de impunidade.

Figura 4

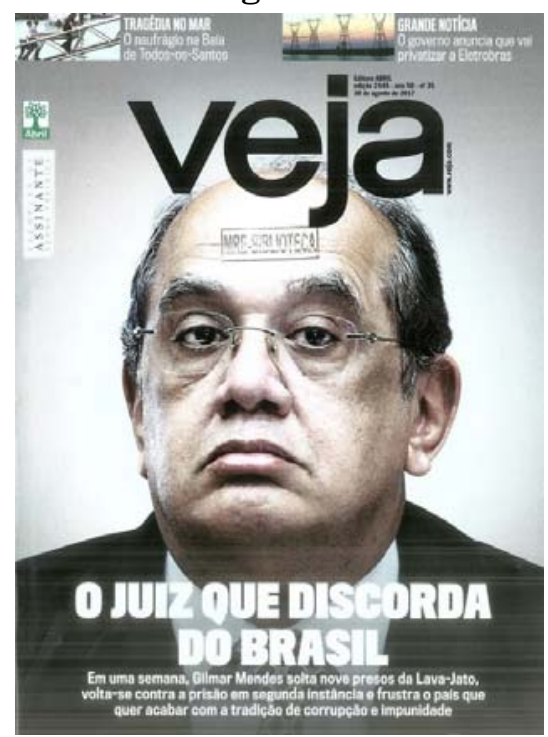

Fonte: Revista Veja, a. 50, n. 35.

Tomou-se por exemplo a revista Veja, mas outras revistas de circulação nacional poderiam ser mencionadas, como a revista Época ${ }^{5}$ e a revista IstoÉ ${ }^{6}$. Essas revistas reproduziam em seus leitores, muitos deles leigos em relação a direitos e garantias constitucionalmente instituídos, uma percepção superficial do direito e da magistratura. Foi produzida, portanto, uma percepção de que a magistratura deve ser parcial no que diz respeito ao posicionamento sobre conflitos sociais: são os "bons" magistrados, considerados "[...] pessoas de boa fé e honestas, que atuam na perspectiva do aumento dos danos àqueles que respondem a processos penais" (CARVALHO, 2017, p. 10). Ocorre que tal percepção revelava mais do que a esperada parcialidade dos magistrados, esteve estampada nas capas que trataram de assuntos referentes às decisões do Poder Judiciário a parcialidade do olhar desenvolvido por tais revistas.

Atualmente reportagens estão produzindo conteúdo com a intenção de levantar dúvidas sobre toda atuação da operação Lava Jato. Em 09/06/2019,

\footnotetext{
5 Ver a revista Época n. 891, de 06/07/2015.

${ }^{6}$ Ver a revista IstoÉ, v.41, n. 2557, de 20/12/2018.
} 
o site The Intercept Brasil publicou a reportagem intitulada "Como e por que o Intercept está publicando chats privados sobre a Lava Jato e Sergio Moro". Nessa ocasião o site The Intercept Brasil explicou estar tratando de "[...] discussões internas e atitudes altamente controversas, politizadas e legalmente duvidosas da força-tarefa da Lava Jato, coordenada pelo procurador renomado Deltan Dallagnol, em colaboração com o atual ministro da Justiça, Sergio Moro, celebrado a nível mundial”.

Em 05/07/2019 o site The Intercept Brasil apresentou a reportagem intitulada "Intercept e Veja publicam reportagem de capa que mostra impropriedades em série - e inéditas - de Sergio Moro na Lava Jato" (ver Figura 5). Nessa ocasião repórteres do Intercept e da revista Veja (a mesma que exaltou o ex-juiz Sérgio Moro) “[...] trabalharam em conjunto para produzir uma reportagem abrangente e minuciosa, [...] demonstrando que o então juiz e hoje ministro Sergio Moro atuou repetidamente de forma imprópria e antiética em sua conduta como juiz”.

Figura 5

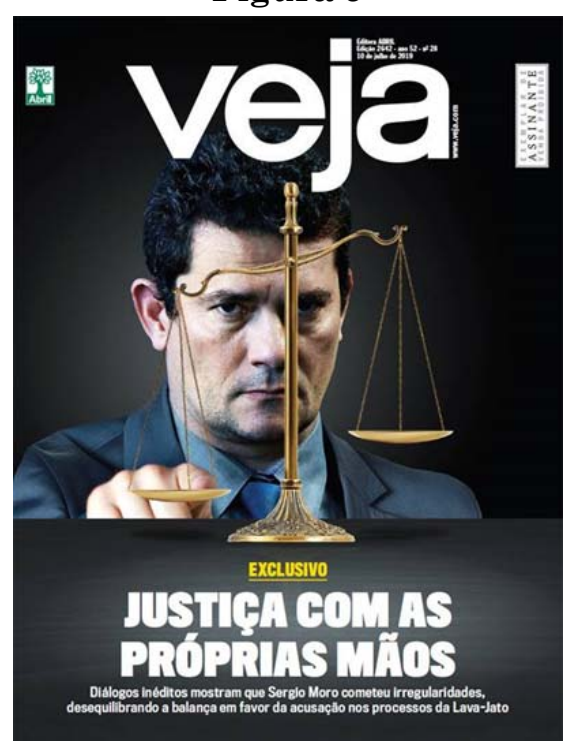

Fonte: Revista Veja, a. 52, n. 28.

Abaixo do título da edição, a revista Veja afirma que "diálogos inéditos mostram que Sérgio Moro cometeu irregularidades, desequilibrando a balança em favor da acusação nos processos da Lava-Jato”. Agora o ex-juiz 
já não é apresentado como um herói, embora ainda possa ser visto dessa forma pela parte considerável da sociedade. A afirmação de haver um desequilíbrio da balança em favor da acusação, considerando a forma como a operação Lava Jato era retratada por boa parte da mídia, foi exatamente a causa da revista Veja ter estampado o rosto do ex-juiz Sérgio Moro como um salvador. Então, a reportagem da revista Veja em parceria com The Intercept Brasil parece ser um contrassenso em relação as antigas publicações da revista, pois em cada capa tratando sobre a Lava Jato ela enaltecia a desregulação da balança da justiça.

A discussão centrada em quem quer prender e quem quer soltar esquece de observar um requisito crucial em qualquer decisão judicial: o respeito ao ser humano7, construindo nos órgãos judiciais uma "[...] tendência de não aplicar as leis que beneficiam o condenado [...]" (CARVALHO, 2017, p. 33). No entanto, com um olhar atento ao que acontece longe dos holofotes, seria possível perceber magistrados preocupados com a redução dos danos aos que se encontram sob a perseguição penal estatal. 8 A lógica de não aplicar leis benéficas tem serventia à condenação, pois qualquer juiz pode determinar a prisão de alguém quando todo o restante quer aquela prisão, “[...] basta fundamentar na retórica da 'gravidade do crime', na existência do 'clamor social', para aplacar 'o sentimento de impunidade"' (CARVALHO, 2017, p. 31). Difícil é absolver quando todos ao redor pedem a condenação.

A tendência pela punição, característica de processos que tratam de corrupção de políticos é reproduzida em diversos outros processos criminais.

\footnotetext{
7 É importante sempre relembrar o respeito ao ser humano, principalmente em tempos como esses, onde "[...] o Poder Judiciário se transformou em uma espécie de tábua de salvação para os mais diversificados males que atormentam a alma humana. Conquanto todas as esperanças sejam depositadas na decisão judicial, prolatar sentenças nem sempre significa pacificar conflitos" (AMBROSIO, 2012. p. 502).

8 A Terceira Câmara Criminal do TJRS (Tribunal de Justiça do Rio Grande do Sul) ao decidir o Agravo em Execução n. 70078104312, sobre horas trabalhadas do preso em dias com carga horária inferior a seis horas, por exemplo, interpretou a LEP (Lei de Execução Penal) de forma mais benéfica ao réu (RIO GRANDE DO SUL, 2018).
} 


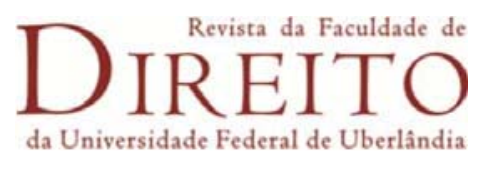

Além do exemplo já apresentado (aquele do réu Dimas), um artigo retrata outras situações reais, como um processo decorrente de "uma denúncia criminal por porte ilegal de arma feita contra um cidadão que tentou suicídio em sua própria casa, desgostoso que estava com o iminente abandono de sua esposa amada (e o juiz o condenou à pena de um ano e dois meses de prisão)" (STRECK, 2006, p. 264).

Portanto, os indícios encontrados indicam que a motivação da magistratura, ao proferir sentenças condenatórias no âmbito da justiça criminal, estaria associada à assimilação do senso comum da sociedade por parte da magistratura

\section{A motivação de uma sentença criminal condenatória}

Pareceu ser necessário compreender o que levaria a magistratura assimilar o senso comum da sociedade. Dessa forma, considerou-se, primeiramente, dois tópicos que poderiam influenciar na relação do magistrado com a sociedade: a origem social e o a formação jurídica.

Para realizar a análise desses tópicos recorreu-se à teoria sociológica de Pierre Bourdieu. Acreditou-se que através dos conceitos de habitus, campos e capital, seria possível compreender de forma adequada os tópicos que escolhidos para análise. Cabe estabelecer o que se compreendeu por cada conceito neste trabalho. Compreendeu-se que o habitus é "[...] princípio gerador de práticas objetivamente classificáveis e, ao mesmo tempo, sistema de classificação (principium divisionis) de tais práticas" (BOURDIEU, 2013, p. 162). Entendeu-se também que o habitus pode ser representado em duas dimensões distintas ${ }^{9}$.

Entendeu-se os campos como "espaços estruturados de posições (ou de postos) cujas propriedades dependem da sua posição nesses espaços e que

\footnotetext{
9 Ter o habitus representado em duas dimensões distintas possibilita "[...] pensar o habitus do indivíduo moderno sendo forjado pela interação de distintos ambientes, em uma configuração longe de oferecer padrões de conduta fechados" (SETTON, 2002. p. 66).
} 
podem ser analisadas independentemente das características dos seus ocupantes [...]" (BOURDIEU, 2003. p. 119). A importância dos campos está compreendida na insuficiência do habitus para a constituição da ação, ele atua como instrumento de propulsão e não pode, deste modo, “[...] ser considerado isoladamente dos mundos sociais particulares, ou 'campos', no interior dos quais evolui" (WACQUANT, 2007, p. 69). O conceito de habitus, portanto, somente se torna completo se compreendido no interior dos campos.

Apesar do habitus ser adquirido pelos indivíduos no interior dos campos sociais, compreendeu-se que ele é também a própria existência do agente, de modo que, o habitus de cada pessoa corresponde a sua própria história, mas também ao seu presente e as suas possibilidades de seu futuro. Pode-se realizar essa interpretação sobre o conceito de habitus, pois "o recurso à noção de habitus, um velho conceito aristotélico-tomista que repensei completamente, como uma maneira de escapar dessa alternativa do estruturalismo sem sujeito e da filosofia do sujeito" (BOURDIEU, 2004, p. 22).

Ou seja, o conceito de habitus contempla duas dimensões distintas: os campos sociais e os indivíduos. A estes "o habitus individual stricto sensu, referente à constelação particular de disposições socialmente adquiridas de comportamento e sentido que é propriedade única de um indivíduo [...]”, aos campos "[...] um habitus de grupo, relativo àqueles caracteres aprendidos que os indivíduos compartilham com os demais membros da mesma formação coletiva" (PETERS, 2010. p. 12).

Sendo assim, tratar da origem social do magistrado, é tratar de sua história, e assim, de seu habitus individual stricto sensu. Esse habitus torna cada pessoa um agente singular, mas também aproxima agentes submetidos a experiências semelhantes, pois ele é uma ferramenta "[...] que auxilia a apreender uma certa homogeneidade nas disposições, nos gostos e 
preferências de grupos e/ou indivíduos produtos de uma mesma trajetória social" (SETTON, 2002, p. 64).

Compreende-se que a aproximação de agentes submetidos a experiências semelhantes permite enxergar as diferentes classes sociais, e que tais experiências são propiciadas a agentes portadores de capitais equivalentes. Não apenas o capital econômico, pois “capital” para Bourdieu ultrapassa os limites da economia. O acúmulo de capital econômico pode conduzir uma classe ao domínio, no entanto, isso não depende apenas deste capital.

As diferenças existentes entre uma classe dominante e outra dominada "[...] encontram sua origem no volume global do capital (capital econômico, capital cultural e, também, capital social) como conjunto de recursos e poderes efetivamente utilizáveis [...]" (BOURDIEU, 2013, p. 107). Bourdieu reconhece a importância do capital econômico, mas não se retém a estudar apenas ele, e "[...] fica claro que a preocupação de Bourdieu é com o capital simbólico que engloba os capitais cultural e social” (TRIGO, 1998, p. $50)$.

A importância do capital econômico sem dúvida se dá pela própria forma capitalista de organização social. Já a importância do capital cultural é estabelecida através de suas três formas de existência: no estado incorporado; objetivado; e institucionalizado. O capital cultural tem a maior parte de suas propriedades "[...] em seu estado fundamental, está ligado ao corpo e pressupõe sua incorporação" (BOURDIEU, 2007, p. 74 - grifo nosso). Nessa lógica, o acúmulo do capital cultural é algo que leva tempo, o agente, e somente ele, pode realizar o trabalho de inculcação e assimilação, "[...] tal como o bronzeamento, essa incorporação não pode efetuar-se por procuração" (BOURDIEU, 2007, p. 74).

O capital cultural incorporado começa a ser adquirido na infância com as relações familiares (sentido em que pode ser transmitido hereditariamente). De modo que, o processo de incorporação desse capital 
fixa no agente o habitus familiar, e com isso o habitus da classe em que sua família está inserida. ${ }^{10}$

A existência do capital cultural objetivado usa como suporte objetos materiais, o capital não se torna o objeto, mas se insere nele, está contido em "[...] escritos, pinturas, monumentos etc., é transmissível em sua materialidade" (BOURDIEU, 2007, p. 77). De qualquer forma esse capital cultural objetivado necessita ser incorporado pelo agente, ${ }^{11}$ pois "para possuir máquinas, basta ter o capital econômico; para se apropriar delas e utilizá-las de acordo com sua destinação específica [...], é preciso dispor, pessoalmente ou por procuração, de capital incorporado" (BOURDIEU, 2007, p. 77).

Neste momento já se tornava evidente que era preciso descartar a consideração exclusiva da origem social da magistratura para se compreender a assimilação que ela faz do senso comum da sociedade. Reconhece-se que os magistrados não poderiam ser oriundos de uma mesma classe social, e pesquisas demonstram isso: metade dos juízes possuíam suas origens em famílias que algum membro ocupa ou ocupou cargo no setor público, entre esses, 47,5\% eram filhos de pais com curso superior. Dentre os juízes originários de famílias do setor privado, apenas 18,9\% possuíam pai com algum curso superior (VIANNA et al., 2003, p. 8). Outra pesquisa demonstrou que $42 \%$ das mães e $51 \%$ dos pais de magistrados possuem

10 Está-se tratando de um aprendizado quase natural e automático da cultura, que é distinguível de outras formas de aprendizado imposto, "ele confere a certeza de si, correlativa à certeza de deter a legitimidade cultural, verdadeiro princípio do desembaraço ao qual identificamos a excelência; ele produz uma relação mais familiar, ao mesmo tempo mais próxima e mais desenvolta, com a cultura, espécie de bem de família que sempre conhecemos e do qual nos sentimos o herdeiro legitimo: a música não são os discos e a eletrola dos vinte anos, graças aos quais descobrimos Bach e Vivaldi, mas o piano da família, ouvido desde a infância e vagamente praticado até a adolescência; a pintura não são os museus, de repente descobertos no prolongamento de um aprendizado escolar, mas o cenário do universo familiar" (BOURDIEU, 1983, p. 97).

11 Entende-se com isso que "[...] os bens culturais podem ser objeto de uma apropriação material, que pressupõe o capital econômico, e de uma apropriação simbólica, que pressupõe o capital cultural. Por consequência, o proprietário dos instrumentos de produção deve encontrar meios para se apropriar ou do capital incorporado que é a condição da apropriação específica, ou dos serviços dos detentores desse capital" (BOURDIEU, 2007, p. $77)$. 
escolaridade alta, e que "um quinto dos magistrados têm familiares na carreira" (CNJ, 2018, p. 15-16).

Sendo assim, não se conseguiu constatar que a origem social dos magistrados teria proporcionado experiências semelhantes a eles, pelo contrário, as diferentes origens sociais dos magistrados não são explicativas das sentenças criminais condenatórias. De modo que não se conseguiria explicar a assimilação do senso comum da sociedade por parte da magistratura a partir da compreensão da origem social dos magistrados, pois a mesma não é homogênea. Restou, então, abordar a formação jurídica do magistrado.

Quando se trata da formação jurídica dos magistrados, está se tratando, obrigatoriamente, de uma formação de nível superior, e a aquisição de um diploma de nível superior, independentemente do curso, é a aquisição de capital cultural institucionalizado. $\mathrm{O}$ estado institucionalizado é, portanto, uma maneira peculiar de objetivação do capital cultural que se estabelece na forma de um diploma, e "[...] é um dos modos de neutralizar certas propriedades devidas ao fato de que, estando incorporado, ele tem os mesmos limites biológicos de seu suporte" (BOURDIEU, 2007, p. 78). O diploma certifica a "[...] competência cultural que confere ao seu portador um valor convencional, constante e juridicamente garantido no que diz respeito à cultura [...]" (BOURDIEU, 2007, p. 78).

Compreende-se que o capital cultural institucionalizado é instituído por uma "magia coletiva”, pensa-se, então, em concurso público “[...] que, a partir do continuum das diferenças infinitesimais entre as performances, produz descontinuidades duráveis e brutais, do tudo ao nada, como aquela que separa o último aprovado do primeiro reprovado [...]” (BOURDIEU, 2007, p. 78). Nesse contexto, a diferença instituída é a “[...] diferença entre a competência estruturalmente reconhecida e garantida e o simples capital cultural, constantemente intimado a demonstrar seu valor" (BOURDIEU, 2007, p. 78). 
Conseguiu-se encontrar na formação jurídica dos magistrados uma exigência semelhante a todos eles: a aquisição de um volume mínimo de capital cultural institucionalizado é homogênea. Ou seja, acessar os quadros da magistratura exige que o agente tenha adquirido previamente o diploma do curso de graduação em Direito. Mas nem todos os agentes portadores desse diploma conseguem acessar a magistratura, dessa forma, não bastaria apenas esse volume de capital cultural institucionalizado, pois é exigido do agente determinado conhecimento, o qual é posto à prova em um concurso público. Não se está referindo à qualidade ou quantidade do conhecimento, mas sim à forma específica de cobrança no concurso público, o que exige dos agentes uma exaustiva preparação, semelhante àquela exigida do atleta que se prepara para uma competição importante.

A forma específica de cobrança do conhecimento em um concurso público para a magistratura demonstra que, além do diploma de Direito, a experiência de preparação para o concurso é mais uma semelhança existente entre os magistrados. Ocorre que, ao se tentar compreender a assimilação do senso comum da sociedade por parte da magistratura a partir da formação jurídica dos magistrados ${ }^{12}$, percebeu-se que ela (a formação jurídica) proporcionaria um maior afastamento do agente em relação à sociedade, do que de fato uma aproximação. Então, o "[...] que se ensina na faculdade de direito? Em primeiro lugar, lei, jamais direito" (FONTAINHA, 2014, p. 40).

O magistrado, assim como qualquer agente jurídico, egressa da faculdade de Direito sem ter adquirido senso crítico capaz de impactar o campo jurídico. Não se está falando apenas da ausência de disciplinas que proporcionem oportunidade de aquisição de senso crítico, existe na formação jurídica uma "[...] inominável defasagem em termos pedagógicos e a profunda distância entre o saber jurídico e a realidade social" (CARVALHO, 2013, p. 58).

${ }^{12}$ Cf. Garcia (2014). 
O senso crítico, portanto, necessita ser inculcado no magistrado, o que é possível fazer, por exemplo, através da pós-graduação stricto sensu ou através da conquista de capital cultural institucionalizado de outra área do conhecimento, que estimulasse o pensamento crítico em seu processo de aquisição. Em 2018 apenas 19\% dos magistrados brasileiros possuíam pósgraduação stricto sensu, 6,6\% possuíam graduação em Ciências Sociais, Sociologia, Antropologia, ou Ciência Política, e 2\% em Psicologia (CNJ, 2018. p. 23-24). Diante disso, aparentemente ao menos um quarto dos magistrados adquiriram senso crítico em outra formação além da graduação em Direito (ou ao menos, tenham recebido a oportunidade de adquiri-lo), razão pela qual não se poderia falar numa total inexistência de senso crítico na magistratura, mesmo que ele não tenha sido adquirido durante a formação jurídica.

Certamente a ausência de senso crítico na formação jurídica dos agentes jurídicos contribui para explicar a tendência que a magistratura tem "[...] de não aplicar as leis que beneficiam o condenado [...]" (CARVALHO, 2017, p. 33). No entanto, a compreensão da formação jurídica dos magistrados parece insuficiente para se explicar a assimilação do senso comum da sociedade por parte da magistratura, pois, apesar de ser uma experiência semelhante a todos os magistrados, um quarto deles possui mais do que a tradicional formação no curso de Direito.

Precisava-se, então, pensar em alguma experiência que fosse comum a todos os magistrados, e não haveria experiência mais comum aos magistrados do que a própria magistratura. A partir disso, analisou-se o campo jurídico para entender como a magistratura se situa nele.

Entende-se o campo jurídico como "[...] o lugar de concorrência pelo monopólio do direito de dizer o direito ${ }^{13}$, quer dizer, a boa distribuição (nomos) ou a boa ordem [...]" (BOURDIEU, 2005, p. 212). Nessa disputa pelo monopólio do capital específico do campo jurídico o magistrado leva

\footnotetext{
${ }^{13}$ Capital específico do campo jurídico.
} 
vantagem, pois a posição dele é de tamanha distinção, tanto em relação à sociedade quanto em relação aos demais agentes de seu próprio campo, que ao seu redor se estabeleceu o que se pode chamar de um campo dentro do campo jurídico: o campo judicial. É especificamente nesse campo que o espaço social se organiza e transmuta, deixa de ser um conflito entre partes e passa a ser um debate entre agentes atuando por procuração, e sempre buscando convencer o agente dominante (o juiz) que a sua versão e fundamentação dos fatos são as mais coerentes (BOURDIEU, 2005, p. 229).

Em cada experiência no interior do campo judicial o agente dominado do campo jurídico percebe a escassez de seu volume de capital específico, assim, o seu direito de dizer o direito ${ }^{14}$ parece ser ínfimo. Na verdade, esse agente dominado geralmente se conforma, pois, a sua formação jurídica o orienta a ter essa atitude em relação ao sistema, e o seu trabalho é tãosomente recorrer a precedentes na tentativa de melhor fundamentar a versão dos fatos que defende (BOURDIEU, 2005. p. 230).

Se o agente dominado do campo jurídico, que adquiriu o capital cultural institucionalizado necessário para acessá-lo, não é capaz de acumular o capital específico de seu campo a ponto de nele causar alguma transformação, menos condições teria algum agente alheio a esse campo. $\mathrm{O}$ capital do campo jurídico em relação a esse agente tem valor logo no "dizer", e não estritamente no "direito de dizer", há uma distinção imensa que se faz através da linguagem, e esse desvio "[...] nada tem de acidental; ele é constitutivo de uma relação de poder, que fundamenta dois sistemas diferentes de pressupostos, de intenções expressivas, numa palavra, duas visões do mundo" (BOURDIEU, 2005, p. 226).

Constatou-se com isso que o magistrado se encontra no topo de seu campo específico, que a sua formação jurídica, assim como a do restante dos agentes desse campo, induz a manutenção do sistema, compreendeu-se

\footnotetext{
${ }^{14}$ Utilizando a expressão de Bourdieu (2005, p. 212).
} 


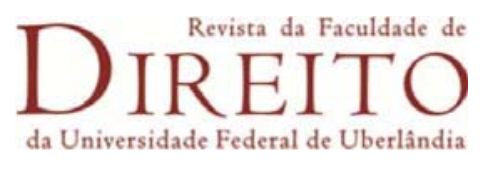

também que as vantagens relativas a sua função pública são excessivas ${ }^{15}$. Certamente o magistrado não é carente de capital economico e exerce o monopólio do capital específico de seu campo. Essa constatação não permite explicar a assimilação do senso comum da sociedade por parte da magistratura. No entanto, ainda faltava ser analisado um capital: o capital social.

Por capital social se entende "[...] o conjunto de recursos atuais ou potenciais que estão ligados à posse de uma rede durável de relações mais ou menos institucionalizadas de interconhecimento e de inter-reconhecimento [...]” (BOURDIEU, 2007, p. 67 - grifo nosso). Ou seja, a vinculação de um agente "[...] a um grupo, como conjunto de agentes que não somente são dotados de propriedades comuns ${ }^{16}$ [...] mas também são unidos por ligações permanentes e úteis" (BOURDIEU, 2007, p. 67).

A dimensão do capital social que cada agente possui individualmente é condizente com a "[...] extensão da rede de relações que ele pode efetivamente mobilizar e do volume do capital (econômico, cultural ou simbólico) que é posse exclusiva de cada um daqueles a quem está ligado" (BOURDIEU, 2007, p. 67). Percebe-se, então, que o capital social não depende exclusivamente de seu agente portador, depende preponderantemente do volume dos capitais dos agentes inseridos em sua rede. Essa rede de relações é resultado "[...] de estratégias de investimento social consciente ou inconscientemente orientadas para a instituição ou

\footnotetext{
15 Essa afirmação pode ser observada em números: "o Supremo foi mais ativo em combater os interesses de outras carreiras públicas que não as da justiça - julgou total ou parcialmente procedente $52 \%$ das ações que combatiam interesses corporativos das demais carreiras públicas, $45 \%$ das ações que combatiam interesses das demais carreiras da justiça e 36\% das ações que combatiam interesses da magistratura. Entre as ações que defendiam interesses corporativos, o STF julgou procedente, no todo ou em parte, $42 \%$ das ações que defendiam interesses da magistratura, 38\% das ações que defendiam os interesses das demais carreiras da justiça e $25 \%$ das ações que defendiam interesses das demais carreiras públicas. [...] Esses dados reforçam a constatação de que o Supremo Tribunal Federal desempenhou o papel de efcaz órgão de deliberação corporativa" (OLIVEIRA, 2016, p. 128). 16 Essas propriedades dos agentes são "[...] passiveis de serem percebidas pelo observador, pelos outros ou por eles mesmos" (BOURDIEU, 2007, p. 67).
} 
reprodução de relações sociais diretamente utilizáveis [...]” (BOURDIEU, 2007, p. 68).

Apesar do magistrado não ser um agente eleito, seria possível dizer que a assimilação do senso comum da sociedade, que o faz incorporar aquela "fúria persecutória espetacular" (CARVALHO, 2017, p. 10), advém de sua necessidade em acumular o único capital que não é totalmente dependente de suas próprias ações: o capital social. Reconhecer tal suposição é admitir que o magistrado é influenciado pela sociedade, ou ao menos por uma parte dela. O magistrado necessitaria dessa relação em seu próprio proveito e não propriamente em proveito do conjunto social. Ao caracterizar um capital social, a ligação tende a se tornar permanente e útil, como se agora a magistratura estivesse preocupada com alguma aprovação social.

Ocorre que a preocupação da magistratura não está relacionada com a aprovação social, pois "o fato de estar ou de se sentir autorizado a falar do 'povo' ou para o 'povo'17 pode constituir, por si só, uma força nas lutas internas dos diferentes campos [...]" (BOURDIEU, 2004, p. 181). Acredita-se que a assimilação do senso comum da sociedade por parte da magistratura é, para esta, simplesmente uma estratégia, utilizada talvez de forma inconsciente para reforçar a sua posição dominante dentro do campo jurídico. ${ }^{18}$

É através do habitus que as estratégias são realizadas, mesmo que elas não signifiquem o "[...] produto de uma aspiração consciente de fins

${ }^{17}$ Compreende-se tal expressão em seu "[...] duplo sentido: para o 'povo' e no lugar do "povo"' (BOURDIEU, 2004, p. 181).

18 Utiliza-se aqui a compreensão de que "a noção de estratégia é o instrumento de uma ruptura com o ponto de vista objetivista e com a ação sem agente que o estruturalismo supõe (recorrendo, por exemplo, à noção de inconsciente). Mas pode-se recusar a ver a estratégia como o produto de um programa inconsciente, sem fazer dela o produto de um cálculo consciente e racional. Ela é produto do senso prático como sentido do jogo, de um jogo social particular, historicamente definido, que se adquire desde a infância, participando das atividades sociais [...], e outros lugares com certeza, dos jogos infantis. $\mathrm{O}$ bom jogador, que é de algum modo o jogo feito homem, faz a todo instante o que deve ser feito, o que o jogo demanda e exige. Isso supõe uma invenção permanente, indispensável para se adaptar às situações indefinidamente variadas, nunca perfeitamente idênticas. $\mathrm{O}$ que não garante a obediência mecânica à regra explícita, codificada (quando ela existe)" (BOURDIEU, 2004, p. 81). 
explicitamente colocados a partir de um conhecimento adequado das condições objetivas, nem de uma determinação mecânica de causas, mostram-se objetivamente ajustadas à situação" (BOURDIEU, 2004, p. 23). Através dessa perspectiva entende-se que a assimilação do senso comum não ocorre de forma unilateral.

O habitus, produzindo estratégias, “[...] como sentido do jogo é jogo social incorporado, transformado em natureza. Nada é simultaneamente mais livre e mais coagido do que a ação do bom jogador" (BOURDIEU, 2004, p. 82). E o magistrado é um bom jogador, de modo que o jogador "[...] fica naturalmente no lugar em que a bola vai cair, como se a bola o comandasse, mas, desse modo, ele comanda a bola” (BOURDIEU, 2004, p. 82). O que se quer dizer com isso: a magistratura assimila menos o senso comum da sociedade, do que a sociedade assimila o "senso comum" da magistratura.

Por toda parte pessoas falando de processos que não entendem, de penas as quais nunca foram submetidas e da necessidade do rigor punitivo em um país com índices de encarceramento como o do Brasil, e a mídia impressa que analisada demonstra isso. Percebeu-se, então, que a falta de senso crítico dos magistrados é reproduzida na sociedade através da assimilação do "senso comum" da magistratura.

Diante disso, quando a sentença criminal condenatória de Dimas foi proferida, não se estava apenas aplicando burocraticamente a legislação penal vigente, tampouco era atendido o calmor social, atendia-se ao "senso comum" da magistratura: composto por um olhar preponderantemente acrítico. Então, a maioria da parte consideravel da sociedade incorpora a neurose que explode no campo judicial: uma fúria persecutória espetacular outra vez, o "senso comum" da magistratura afetando o espaço social -, transformando-o em um espaço de irracionalidade onde a violência se 
estabelece como espetáculo midiático e as desigualdades sociais são ignoradas. 19

\section{Conclusão}

Foi abordado como a neurose da sociedade pode conter a motivação para uma sentença criminal condenatória ao se endaguar o que estaria motivando a magistratura. Apresentou-se o exemplo do réu Dimas, um ladrão condenado pelo roubo de um celular e $\mathrm{R} \$ 40,00$, conduta que o Estado não deixaria passar impune.

Para compreender a motivação da magistratura observou-se como o cenário jurídico mais recente do Brasil é apresentado à sociedade. Buscouse, então, indícios na mídia impressa, não especializada na área do direito e que tivesse circulação nacional. Percebeu-se na mídia a existência de um apelo pela punitividade, especificamente em relação à corrupção. No entanto, foi possível perceber que a punitividade aplicada à corrupção de políticos é também aplicada a outras condutas sociais, independentemente das novas publicações sobre supostas ilegalidades ocorridas na condução das operações que dizem combater a corrupção. Com isso, percebeu-se que a motivação da magistratura para proferir sentenças criminais condenatórias não poderia excluir a sociedade.

Ao elencar dois tópicos (origem social e formação jurídica dos magistrados) como possiveis motivadores das sentenças criminais condenatórias, inseriu-se a teoria sociológica de Pierre Bourdieu. A análise dos conceitos de habitus, campos e capital possibilitou perceber que a origem social e a formação jurídica dos magistrados não poderiam conter a motivação para que proferissem sentenças criminais condenatórias.

\footnotetext{
${ }^{19}$ Empregou-se de maneira metafórica a colocação realizada por Carvalho (2017, p. 10): "a maioria de nós incorpora a neurose que explode na sociedade civil: uma fúria persecutória espetacular - outra vez, o senso comum invadindo o espaço do jurista -, transformando-o em agente da irracionalidade que percebe o fenômeno violência como espetáculo midiático"
} 
Buscou-se, então, na experiência que seria a mais comum a todos os magistrados: a própria magistratura. Com essa análise percebeu-se que o magistrado é o agente dominante de seu campo específico, e que no único capital que não depende exclusivamente de suas ações (o capital social) poderia estar a motivação das sentenças criminais condenatórias. Estabelecido a partir de uma rede de relações, o capital social é útil à magistratura, como se ela, mesmo não sendo composta por agentes eleitos, estivesse agora preocupada com alguma aprovação social.

Mas a preocupação da magistratura não está relacionada com a aprovação social. Trata-se simplesmente de uma estratégia, utilizada talvez de forma inconsciente para reforçar a posição dominante da magistratura. $\mathrm{O}$ magistrado, como bom jogador, comanda o jogo, mesmo que pareça estar sendo comandado pelo jogo. Então conseguiu-se compreender que a magistratura assimila o senso comum da sociedade menos do que a sociedade assimila o "senso comum" da magistratura. De tal modo que o efeito social de uma sentença criminal condenatória não é apenas aprisionar o condenado fisicamente, ela o aprisiona em uma posição de submissão extrema para que a ocupação da posição dominante permaneça inalterada.

\section{Referências}

ABERRAÇÃO Suprema (capa). IstoÉ, v.41, n. 2557, 20 dez. 2018. Disponível em: < https://istoe.com.br/edicoes/ >. Acesso em: 4 mar. 2019.

AMBRosio, Graziella. Psicologia do juiz. Revista de Direito Econômico e Socioambiental, v. 3, n. 2, pp. 491-503, 2012.

BANCO NACIONAL DE MONITORAMENTO DE PRISÕES. Cadastro nacional de presos. Brasília: Conselho Nacional de Justiça, 2018. Disponível em: http://www.cnj.jus.br/files/conteudo/arquivo/2018/08/57412abdb54eba909b3e1819fc4c3ef4.p df. Acesso em: 28 dez. 2018.

BOURDIEU, Pierre, 1930-2002. A distinção: crítica social do julgamento. Tradução Daniela Kern; Guilherme J. F. Teixeira. 2. ed. Porto Alegre: Zouk, 2013.

Coisas ditas. Tradução Cássia R. da Silveira; Denise Moreno Pegorim. São Paulo: Brasiliense, 2004. Brasil, 2005.

O poder simbólico. Tradução Fernando Tomaz. $8^{a}$ ed. Rio de Janeiro: Bertrand 


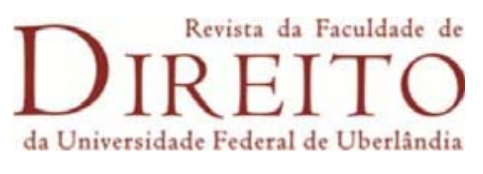

. Os três estados do capital cultural. Tradução Magali de Castro. In: NOGUEIRA, Maria Alice; CATANI, Afrânio (org.). Escritos de educação. 9. ed. Petrópolis, RJ: Vozes, 2007. pp. 71-79.

Século, 2003 .

Questões de sociologia. Tradução Miguel Serras Perreira. Lisboa: Fim de

Sociologia. ORTIZ, Renato (org.). Tradução Paula Monteiro; Alícia Auzmendi. São Paulo: Atica, 1983.

CARVALHO, Amilton Bueno de. Eles, os juízes criminais, vistos por nós os juízes criminais. 3. ed. Rio de Janeiro: Lumen Juris, 2017.

CARVALHO, Salo de. Antimanual de criminologia. 5. ed. São Paulo: Saraiva: 2013.

CNJ. Perfil sociodemográfico dos magistrados brasileiros. Brasília: CNJ, 2018.

FONTAINHA, Fernando de Castro. Todos eles juízes: um monopólio baseado na eficácia simbólica. In: Raúl Enrique Rojo. Por trás da toga: magistratura, sociedade e política no Brasil hoje. Porto Alegre: Dom Quixote, 2014, pp. 34-60.

GARCIA, Mariana Dutra de Oliveira. A criminologia no ensino jurídico no Brasil. 2014. 171 f. Dissertação (Mestrado em Direito) - Centro de Ciências Jurídicas. Universidade Federal de Santa Catarina, Florianópolis, 2014.

GREENWALD, Glenn; POUGY, Victor. Intercept e Veja publicam reportagem de capa que mostra impropriedades em série - e inéditas - de Sergio Moro na Lava Jato. The Intercept Brasil. 2019. Disponível em: https:/theintercept.com/2019/07/05/veja-condutamoro-lavajato/. Acesso em 14 ago. 2019.

GREENWALD, Glenn; REED, Betsy; DEMORI, Leandro. Como e por que o Intercept está publicando chats privados sobre a Lava Jato e Sergio Moro. The Intercept Brasil. 2019. Disponível em: https://theintercept.com/2019/06/09/editorial-chats-telegram-lava-jato-moro/. Acesso em: 11 jul. 2019.

HULSMAN, Louk; CELIS, Jacqueline Bernat de. Penas perdidas. O sistema penal em questão. Tradução Maria Lúcia Karam. 2. ed. Niterói, RJ: Luam. 1997.

JUSTIÇA com as próprias mãos (capa). Veja, edição 2642, ano 52, n. 28, 10 jul. 2019. Disponível em: https://veja.abril.com.br/edicoes-veja/2642/. Acesso em: 14 ago. 2019.

MIQUELETTI, Eliane Aparecida. A presença dos contextualizadores na construção da imagem do Ministro Joaquim Barbosa. Entrepalavras, v. 3, n. 2, pp. 210-223, 2013.

NADA vai pará-lo (capa). Época, n. 891, 6 jul. 2015. Disponível em: https://epoca.globo.com/tempo/noticia/2013/06/capas-de-epoca.html. Acesso em: 4 mar. 2019.

O MENINO pobre que mudou o Brasil (capa). Veja, edição 2290, ano 45, n. 41, 10 out. 2012. Disponível em: http://www.biblioteca.itamaraty.gov.br/periodicos/v/veja/veja-o-meninopobre-que-mudou-o-brasil/. Acesso em: 2 mar. 2019

OLIVEIRA, Fabiane Luci. Agenda suprema: interesses em disputa no controle de constitucionalidade das leis no Brasil. Tempo Social, revista de sociologia da USP, v. 28, n. 1, pp. 105-133, 2016.

PETERS, Gabriel. Humano, demasiado mundano: a teoria do habitus em retrospecto. Teoria \& sociedade, v. 18, n. 1, pp. 8-37, 2010.

RIO GRANDE DO SUL. Terceira Câmara Criminal do Tribunal de Justiça. Agravo em Execução n. 70078104312. Relator: Desembargador Diógenes Vicente Hassan Ribeiro. Porto Alegre, 15 de agosto de 2018. Disponível em: http://www.tjrs.jus.br/buscal. Acesso em: 4 mar. 2019. 
SANTOS, Tamara et al. (orgs.). Levantamento nacional de informações penitenciárias: INFOPEN atualização - julho 2016. Brasília: Ministério da Justiça e Segurança Pública. Departamento Penitenciário Nacional, 2017.

SETTON, Maria da Graça Jacintho. A teoria do habitus em Pierre Bourdieu: uma leitura contemporânea. Revista Brasileira de Educação, n. 20, pp. 60-70, 2002.

SOBREIRO, Pedro. Qual a revista de maior circulação no Brasil? e no mundo?. Super Interessante. 17 out. 2017. Disponível em: https://super.abril.com.br/mundoestranho/qual-a-revista-de-maior-circulacao-no-brasil-e-no-mundol. Acesso em: 3 mar. 2019.

STRECK, Lenio Luiz. A atualidade do debate da crise paradigmática do direito e a resistência positivista ao neoconstitucionalismo. Revista do Instituto de Pesquisas e Estudos, v. 40, n. 45, pp. 257-290, 2006

TRIGO, Maria Helena Bueno. Habitus, campo, estratégia: uma leitura de Bourdieu. Cadernos Ceru, v. 9, pp. 45-55, 1998.

VIANNA, Luiz Werneck et al. Corpo e alma da magistratura brasileira. 3. ed. Rio de Janeiro: Revan, 2003.

WACQUANT, Loïc. Esclarecer o habitus. Educação \& Linguagem, v. 10, n. 16, pp. 63-71, 2007.

Artigo recebido em: 30/09/2019.

Aceito para publicação em: 13/06/2020. 